\title{
A Multidimensionalidade nas Organizações Empresariais: Proposta de um Modelo Analítico
}

\author{
Sérgio Alves
}

\begin{abstract}
Resumo
O modelo proposto neste artigo tem por fundamento teórico o legado de Max Weber, principalmente a sua tipologia da ação social e os seus tipos ideais de dominação, cujos componentes são reelaborados para a construção de instrumental analítico capaz de contribuir para investigar configurações administrativo-organizacionais. O modelo ressalta a coexistência, no interior da organização empresarial, de um conjunto de fenômenos simultaneamente opostos e complementares, em meio a um processo contínuo de organização-interações-reordenamento. A empresa dotada de uma estrutura equiparativo-adaptadora é o tipo-base do modelo, a partir do qual são descritos os subtipos ordenativo-conservador e liberativo-transformador. Este trabalho insere novos elementos no debate sobre como integrar flexibilidade, autonomia e liberdade, que propiciam a inovação e a criatividade, com estabilidade, padronização e regulamentação, que favorecem a disciplina administrativa e o controle gerencial.
\end{abstract}

Palavras-chaves: modelo analítico; tipos ideais; teoria das organizações; multidimensionalidade; análise organizacional.

\begin{abstract}
The model proposed in this article is founded on the legacy of Max Weber. It principally elaborates on his typology of social action and his ideal types of domination. These components are reelaborated into the construction of an analytical instrument capable of contributing to the investigation of organizational-administrative configurations. The model emphasizes the coexistence, within the interior of the business organization, of a set of phenomena simultaneously opposed and complementary, in the middle of a continuous process of organization-interactionrestructuring. The business set up on a Comparative-Adaptive structure is the base type of the model, from which the Ordinance-Conservative and Liberation-Transforming subtypes are described. This article inserts new elements into the debate of how to integrate flexibility, autonomy and liberty, that proportion innovation and creativity, with stability, standardization and regulation, that favor administrative discipline and managerial control.
\end{abstract}

Key words: analytical model; ideal types; organization theory; multidimensionality; organizational analysis. 


\section{INTRODUÇÃO}

A possibilidade objetiva de as estruturas puras de dominação weberianas serem combinadas implica tratar os seus componentes como dimensões de análise, isto é, uma maneira de operacionalizar esta combinação de tipos ideais é considerar seus elementos constitutivos como variáveis de um sistema analítico passíveis de serem associadas em diversos graus (Aron, 1993; Bendix, 1986; Etzioni, 1974; Wolpert, 1950). Com efeito, na realidade se encontram múltiplas combinações de componentes das três estruturas de domínio concebidas por Weber, cujas características são mais bem elucidadas, quando se utilizam expressões, como: carisma familiar (mescla de componentes tradicionais e carismáticos), burocracia patrimonial (agrupamento de componentes legais e tradicionais), burocracia carismática ou carisma institucional (mistura de componentes racional-legais e carismáticos). Por via de conseqüência, a subsistência das relações de domínio dessa natureza fundamenta-se em uma legitimidade assentada também em bases mistas - crença na tradição, na afeição e na legalidade formal, coexistindo em diferentes intensidades.

Em diversas pesquisas de amplo alcance foi verificada a existência dessas estruturas híbridas, das quais ressalto algumas realizadas por autores brasileiros: Faoro (1958, p. 74) comenta que a "herança histórico-cultural brasileira acarreta a prática de um ritualismo formalista de caráter burocrático-patrimonialista, no qual o Estado precede a sociedade”; Uricoechea (1978, p. 302) também identificou "a coexistência de formas tradicionais e racionais, de patrimonialismo e burocracia"; e Cavalcanti (1984, p. 177) observa que, no Brasil, "ao lado de uma legitimidade racional-legal, subsiste amplamente um conteúdo de tradição e de carisma”.

No campo dos estudos organizacionais, especificamente, tem sido utilizada uma abordagem unidimensional, isto é, as organizações são descritas e/ou analisadas tendo em vista a sua maior ou menor aproximação em relação ao tipo ideal de burocracia. Vale dizer, outras estruturas puras de domínio, como a patriarcal e a carismática, não têm recebido dos pesquisadores a atenção devida, muito embora possa ocorrer a presença de seus componentes em configurações organizacionais encontradas na realidade concreta. Dessa forma, a presente proposta de um modelo multidimensional para análise de organizações empresariais contemporâneas justifica-se por possibilitar ao pesquisador a utilização de um instrumento analítico mais abrangente, posto que inclui as dimensões tradição, correspondente à estrutura patriarcal-familiar, e a afetivo-emocional, associada 
à liderança com traços carismáticos, além da dimensão racional-legal, típica da estrutura burocrática.

Encaminharei o delineamento do modelo de organização multidimensional, tendo como ponto de partida as estruturas de dominação de Max Weber, desde que decompostas, de forma que os seus componentes possam ser tratados como variáveis analíticas, reelaborados para serem transpostos para o âmbito microssocial das organizações empresariais e atualizados para se adequarem às circunstâncias do nosso tempo.

\section{Caracterização do Modelo Multidimensional}

Para a caracterização do modelo de organização multidimensional é indispensável antecipar que ele adota uma perspectiva que considera o indivíduo e o sistema-empresa como dimensões estreitamente articuladas e reciprocamente condicionantes. Em outras palavras, as estruturas não são apenas coações sobre a ação, elas também são incentivadoras da ação (Giddens, 1993). Na ambiência microssocial das organizações empresariais, no entanto, se tem de maneira mais evidente a reflexividade dos agentes. Vale dizer, as suas ações estão vinculadas à sua capacidade de auto-reflexão, no sentido de eles exercerem certo monitoramento de suas condutas no interior da empresa. Assim sendo, esses agentes atuam por determinados motivos e são responsáveis por suas ações, apesar das conseqüências não-intencionais do seu agir e malgrado fatores condicionantes incontroláveis, de origem interna ou externa.

Longe de ser simples reordenamento de componentes das estruturas fundamentais de domínio, o modelo multidimensional é representado por uma configuração organizacional-administrativa multifacetada, tríptica e transiente, em cuja anatomia constam elementos caracterizadores do estilo de gestão patriarcal, da liderança com traços carismáticos e da administração burocrática, dinamicamente relacionados entre si e influenciando-se mutuamente em variadas intensidades. Esse desenho estrutural polimórfico, híbrido e mutante resulta da inter-relação de conjuntos de componentes que emergem daqueles tipos ideais, cada um deles impregnando-se com os demais, interpenetrando-se uns com os outros, em múltiplas e covariadas combinações, gerando um equilíbrio dinâmico de antagonismos. O modelo é construído a partir da combinação de componentes dos tipos ideais weberianos, devidamente reelaborados e tratados como conjuntos de variáveis. Para tanto, consideram-se as seguintes situações, em relação às suas dimensões constituintes (carisma, patriarcado e burocracia). 
- Quanto ao carisma. Este se situa entre dois pólos extremos, carisma genuíno e carisma rotinizado (nesta condição o carisma se dilui para assentar-se em bases tradicionais ou racionais). O modelo, porém, opera com a liderança com traços carismáticos mais ou menos mitigados, porquanto não ressalta o ímpeto revolucionário, característica inseparável do carisma puro; nem enfatiza o carisma despersonalizado, que corresponde à noção de carisma objetivado. De qualquer modo, o componente afetivo, que fundamenta a liderança com traços carismáticos, está associado à coesão organizacional interna e à incorporação de um sentido de missão, personificada no líder empresarial.

- Quanto ao patriarcado. A marca indelével dessa estrutura é a tradição e os valores familiares materializados no patriarca. No entanto o senhor patriarcal dispõe de uma área de livre arbítrio, isto é, a vontade do patriarca pode manifestar-se arbitrariamente em várias situações de forma bastante elástica, exceto em relação a algumas normas e costumes invioláveis (Weber, 1999). A extensão do uso dessa liberdade do patriarca sugere que ele pode ter a sua ação menos conduzida objetivamente pela tradição e mais inspirada subjetivamente pela sua vontade própria, o que permite a seguinte qualificação: (1) quando ela é máxima, corresponde ao que chamo de patriarca reformador; (2) quando é intermediária, denomino de patriarca renovador; e (3) quando é mínima, nomeio de patriarca conservador. Oportuno destacar que ao ingrediente tradição está relacionada a ocorrência de uma configuração patriarcal que pode ser traduzida organizacionalmente por uma "associação de indivíduos que, possuindo ou não vínculos de parentesco, estão interligados por laços de confiança, dedicação e lealdade e cooperação” (Ouchi, 1982, p. 86).

. Quanto à burocracia. Constata-se que, na realidade, nenhuma empresa possui o conjunto das características inerentes ao seu tipo ideal, embora este possa ser utilizado como referencial para investigar em que grau uma organização é burocratizada. Para fins do modelo, considera-se o burocrata como mais ou menos rígido (ou flexível), conforme a sua presença e atuação em uma empresa que esteja mais ou menos próxima em relação ao idealtipo burocracia Para ilustrar, as organizações empresariais podem ser classificadas em tipos que vão desde a burocracia mecanizada à adhocracia, passando pelas variações burocráticas denominadas de simples profissional e divisionada (Mintzberg, 1995). De outra parte, convém lembrar que Pugh, Hickson \& Hinnings (1968) identificaram empiricamente, ao final da análise de 52 organizações diversas e com base em três critérios (concentração de autoridade, estruturação de atividades e natureza de controle), tipos organizacionais cujas estruturas apresentavam variadas formas: (1) burocracia plena - alta estruturação das atividades, alta concentração de autoridade, baixa integração dos fluxos de trabalho, alta padronização nos procedimentos de seleção e 
promoção e alta formalização na definição de papéis; (2) burocracia plena nascente, com características semelhantes às anteriores, porém em menor intensidade; (3) burocracia de fluxo de trabalho: alta estruturação das atividades, baixa concentração de autoridade, fraco controle do fluxo de tarefas; (4) burocracia de pessoal, com baixa estruturação das atividades, alta concentração de autoridade, alto controle do fluxo de trabalho; (5) burocracia nascente de fluxo de trabalho, com média estruturação das atividades, muito baixa concentração de autoridade, fraco controle; (6) pré-burocracias de fluxo de trabalho, com baixa estruturação das atividades; alta concentração de autoridade e forte controle das tarefas.

Como empreendimento voltado para o interesse econômico, a organização empresarial é principalmente avaliada quanto aos lucros auferidos, em termos da relação custo-benefício e no que diz respeito a sua capacidade competitiva em um dado mercado. Para tanto, os que fazem a empresa buscam um melhor desempenho, procurando otimizar os meios disponíveis para alcançar os objetivos desejados, pois "a racionalidade diz respeito à maneira pela qual o agente processa ‘economicamente' os recursos de que dispõe” (Reis, 2000, p. 316). Assim, no modelo de organização multidimensional, a presença da racionalidade instrumental está associada com a eficiência técnico-econômica da empresa e manifesta-se sempre a partir de uma adequada articulação entre os meios e recursos em relação a determinados fins. Na realidade, todavia, as informações necessárias a uma decisão racional não são de todo conhecidas, limitando o exercício da racionalidade burocrática (March \& Simon, 1967; Simon, 1971). Além do mais, fatores como percepção, afeto, conflito e emoção contaminam os procedimentos requeridos por aquela racionalidade e impedem que se possa ter antecipadamente uma avaliação exata das conseqüências da ação para a empresa. Dito de outra maneira, com a abordagem multidimensional se procura evitar "o maniqueísmo entre uma orientação voltada para o processo e outra voltada para resultados, entre a subjetividade e a racionalidade instrumental (...) entre o pulsional e o racional“ (Matos, 2000, p. 69), porque todos estes aspectos estão articulados na mesma cena organizacional. Mesmo em organizações empresariais fortemente reguladas por princípios racional-instrumentais e que aglutinam os seus membros em função de interesses materiais, não se tem eliminado a necessidade de confiança entre seus integrantes em relação a seus parceiros econômicos, ou seja, a lógica do mercado, que destaca uma relação entre coisas, não destrói completamente os laços socioafetivos, nem a respeitosa devoção a determinado costumes (Godbout, 1997). Com efeito, a gestão da organização empresarial é permeada por elementos racionais e não-racionais (Motta, 1997).

O modelo multidimensional considera que há sempre presente na empresa certo grau de racionalidade instrumental, ao lado de ingredientes tradicionais e afetivos, 
em variadas intensidades. Por mais forte que seja o anseio pela superação da burocracia, tem-se sempre na organização empresarial um agir voltado para o cálculo utilitário das conseqüências (Dellagnelo \& Machado-da-Silva, 2000), muito embora sempre exista a possibilidade de os sentimentos dos indivíduos afetarem de algum modo a objetividade exigida pela ação racional em relação a fins.

Como o modelo multidimensional é uma representação parcial e incompleta da realidade, ele não reflete uma estrutura que seja conveniente ou adequada a todas as organizações empresariais, em quaisquer condições, assim como também não existe uma única configuração organizacional-administrativa igualmente apropriada para todos os setores ou áreas da organização. Nesse aspecto, o modelo proposto apresenta um ponto de convergência com a perspectiva contingencial, que advoga a variação da configuração organizacionaladministrativa conforme fatores contingenciais, associados à natureza das tarefas, ao tipo de estratégia, ao tamanho, à tecnologia adotada, entre outros. O modelo, todavia, diverge dessa abordagem, na medida em que interesses e preferências dos agentes organizacionais não figuram para os contingencialistas como fatores relevantes e sequer discutem quem toma as decisões ou quais são seus motivos, o que, ao meu ver, empobrece o seu potencial analítico.

O modelo em pauta não corresponde a um todo monolítico, nem a um referencial de excelência, porquanto, dependendo de diversos fatores internos e externos, haverá arranjos estruturais específicos para a situação concreta. Pelo seu caráter explicativo e não-prescritivo, esse modelo nunca poderia aspirar a ser uma configuração organizacional-administrativa de excelência ou que traduzisse uma estrutura ótima, nem é integrado por agentes organizacionais exemplares, e tampouco representa uma agenda que orienta o melhor desempenho para qualquer empresa em qualquer tempo ou lugar. Consoante os propósitos e a razão de ser do negócio, por força de fatores internos e externos, limitativos ou potenciadores, e dependendo dos agentes e grupos de interesse envolvidos, haverá arranjos estruturais específicos, mais ou menos duradouros e adequados a cada situação concreta.

O modelo assimila simultaneamente um controle utilitário e normativo, no qual se exerce, de um lado, um poder tangível e remunerativo, por meio de autoridades burocráticas ou patriarcais que gerenciam retribuições materiais e pecuniárias; e, por outro, opera um poder intangível e normativo, por meio de lideranças que alocam recompensas simbólicas e criam referências de comportamento. No primeiro caso, gera-se nos membros da organização um comportamento de caráter mais calculista e uma participação de natureza utilitária; e, no outro, produz-se um comportamento em que predomina uma orientação motivacional de natureza moral e um comprometimento de caráter afetivo-emocional. 
De qualquer modo, com o propósito de reduzir ambigüidades, incertezas e riscos de desarticulação no interior das organizações empresariais, os seus dirigentes e líderes desenvolvem mecanismos de regulação que explicitam metas e padrões de desempenho, orientam o comportamento no trabalho e estabelecem os limites aceitáveis para iniciativas de mudança. Assim, o modelo incorpora mecanismos de coordenação e controle de caráter híbrido (utilitário e normativo). Esses dispositivos de integração e controle mistos, para indicar e corrigir formas de atuação, são operacionalizados de diversas maneiras, a exemplo de regras e regulamentos, incentivos à interação dos executores de tarefas interdependentes, compartilhamento de crenças e valores organizacionais, manipulação de recompensas ou punições, treinamentos que reforçam a competência tecnológica instalada etc.

Por outro lado, o modelo encerra uma abordagem multidimensional do tempo, ao considerar que o tempo organizacional possui dimensões interligadas de temporalidade, isto é, a ele está associada uma perspectiva que encara os três tempos imbricados entre si: (1) o passado, que acolhe hábitos e costumes consolidados na história da empresa, propicia certa regularidade e estabilidade organizacional, mas apresenta tendência ao imobilismo ou à inércia (o patriarcado, cuja legitimidade assenta na tradição, é estrutura mais voltada para a vivência pretérita); (2) o tempo presente, que corresponde à experiência imediata e ao fluxo contínuo das atividades correntes, embora contenha importantes elementos do preexistente, pode acolher a gênese da mudança adaptativa (a burocracia, apesar de ter regras e rotinas cristalizadas ao longo do tempo, representa o tipo de organização em que predomina o foco no presente); (3) o futuro, que ajuda a apreender o caráter do presente com o qual está implicado, também incorpora parcialmente a experiência pretérita para alimentar o processo de conceber a visão do futuro que se almeja (a liderança com traços carismáticos, pela sua natureza essencialmente transformadora, enfatiza o porvir). Segundo essa noção de tempo, nos momentos cruciais de profunda e radical mudança organizacional, podem ocorrer experiências convivais com forte interação afetivo-emocional dos seus membros, circunstância em que o tempo é percebido de maneira imprecisa, difusa, e não como algo linearmente seqüencial.

\section{O Processo de Organização-interações-reordenamento}

A constante inter-relação das variáveis componentes da burocracia, do patriarcado e do carisma, que caracterizam o modelo de organização 
multidimensional, resulta em dois sistemas de vetores opostos que não se fundem, nem se manifestam alternadamente ou de maneira intermediária. Esses dois conjuntos de tendências contravenientes geram um processo no qual ocorre um enfrentamento entre a conservação e a mudança, a tradição e a contemporaneidade, a estabilidade e a instabilidade, a rigidez e a flexibilidade, a disciplina e a autonomia, a repetição e a originalidade, a centralização e a descentralização, a padronização e a criatividade, a rotina e a inovação.

Um desses conjuntos se refere à conjunção de variáveis associadas com a ordem, estrutura e conservação (tradição, estabilidade, rigidez, disciplina, repetição, centralização, padronização, rotina), que contribuem para a organização empresarial manter a sua estrutura original, reconhecer a sua identidade, resguardar a sua trajetória histórico-cultural, garantir a regularidade de suas operações e preservar o seu acervo de conhecimentos e experiências.

O outro corresponde a uma coleção de variáveis relacionadas com liberdade, ação e mudança (contemporaneidade, instabilidade, flexibilidade, autonomia, originalidade, descentralização, criatividade, inovação), que favorecem na empresa uma reconstrução contínua, objetivando ajustar-se às novas demandas e necessidades que surjam. O relacionamento desses dois conjuntos de vetores antagônicos se expressa por meio de um processo de organização-interaçõesreordenamento que origina uma configuração organizacional-administrativa híbrida, em que não se tem identificado uma primazia permanente do sistemaorganização ou do agente individual e sim um equilíbrio dinâmico ordem-liberdade, estrutura-ação, conservação-mudança.

Dito de outra forma, no interior da organização empresarial, o confronto entre a autoridade instituída e as forças instituintes, representadas por agentes que ameaçam romper o statu quo estabelecido, produz "mudanças que se estruturam provisoriamente em uma nova situação concreta de equilíbrio organizacional, uma síntese mediatizada a ser superada por novas confrontações que se sucederão na continuidade do processo" (Matos, 2000, p. 61). É nessa complexa dinâmica organizacional, entremeada por momentos de dissenso e consenso, conflito e harmonia, que a empresa é continuamente (re)construída.

As mudanças estruturais na empresa não dependem exclusivamente do voluntarismo dos agentes organizacionais, embora eles tenham relativa autonomia para modificar a estratégia e o desempenho da organização que integram. A existência de indivíduos e grupos que se contrapõem, a incerteza das conseqüências de suas ações intencionais e o limitado conhecimento da realidade, ao lado de fatores condicionantes próprios de dada situação, restringem o alcance e alteram os efeitos das iniciativas dos agentes. Mas, independentemente do 
desejo dos seus membros, as organizações empresariais inexoravelmente se transformam, devido a diversos fatores externos, como: alterações mercadológicas impactantes e duradouras, manobras das empresas concorrentes, modificações da legislação, consolidação de novos patamares tecnológicos, ou mesmo por costumes que retornam para se constituírem em guardiões do novo.

A empresa permanentemente procura valer-se de técnicas administrativas e métodos de gestão para tornar os seus membros mais propensos a aderir aos objetivos organizacionais e a exibir uma disposição mais colaborativa. Para tanto, os agentes decisores concebem um "estado desejado” ou visão do negócio, compatível com a missão empresarial; mas esse quadro de referências futuras não é uma opção livre, porquanto é condicionado pela situação existente em termos dos fatores limitantes e facilitadores associados às transformações desejadas. O nível de abrangência e o grau de complexidade da mudança organizacional variam em conformidade com a natureza das modificações pretendidas. Se a área de transformação se refere ao setor técnico-operacional da empresa, os resultados poderão consolidar-se em um menor período de tempo, a partir da utilização de novos equipamentos ou tecnologias e o desenvolvimento de um programa de treinamento específico. Na esfera administrativa, a mudança geralmente ocorre em curto-médio prazo, por meio da gradual adoção de novos procedimentos, da redefinição de tarefas e da capacitação do pessoal para a disseminação do novo método de trabalho; e no âmbito da cultura da empresa, por envolver crenças, valores, símbolos, mitos e rituais, o processo é mais lento e imprevisível (Alves, 1997).

Sob dadas condições, o sistema-organização se transforma por meio da ação, reação e interação dos agentes organizacionais, que possuem motivações as mais diversas e estão sujeitos a sentimentos egoístas ou solidários. Quando eles integram a coalizão de poder que controla a organização, os seus interesses e preferências influenciam significativamente a escolha dos objetivos estratégicos, circunstância em que eles agem mais como ser político do que administrativo (Chanlat, 2000; Freitas, 1999; Motta, 1997). Em todo o caso, "os indivíduos não agem nem interagem feito autômatos ou marionetes (...) sendo antes movidos por crenças ou objetivos, mesmo quando vaga, ambígua e incoerentemente perseguidos (...) mas admitindo-se o fato de que a ação intencional não opera em um vácuo, encontrando-se antes submetida a condicionamentos de toda a ordem” (Gusmão, 2000, p. 244 e 245).

Atualmente, nas empresas, parte dos seus integrantes freqüentemente participa internamente de redes de trabalho multissetoriais e interempresariais, acarretando o surgimento de zonas de interação, de sobreposição e de disjunções que lhes possibilitam escapar de um controle gerencial mais direto e favorecem a conquista de maior autonomia para agir de maneira inovadora e criativa (Enriquez, 1990). 
Tendo em vista a concepção do agente multidimensional, ora ele pode atuar mais como um guardião do statu quo, conservando as rotinas, mantendo os costumes e reagindo às iniciativas descentralizadoras; ora pode agir com o propósito de inovar procedimentos e de criar novos padrões operacionais, combatendo o formalismo e a tradição; ora ele pode procurar um equilíbrio entre regulamentações disciplinadoras e liberdade criativa. Como defensor do precedente estabelecido e de normas e hábitos preexistentes, o agente organizacional conservador apresenta características que o aproximam do burocrata ou do patriarca típicos. Ele adota uma estratégia onde se ressalta a necessidade de garantir a ordem, os costumes e a estabilidade da organização. Agindo como um inovador de práticas administrativas, o agente transformador assemelha-se ao líder com traços carismáticos ou ao patriarca reformista (a qualificação reformista corresponde à maximização da área de livre arbítrio que possibilita ao patriarca manifestar-se de forma bastante elástica, relativamente à tradição da empresa). Ele utiliza uma abordagem que visa a empreender inovações e promover mudanças, mesmo antes de evidenciar-se claramente esta necessidade. Quando o agente adaptador procura um equilíbrio entre a padronização de procedimentos e a livre iniciativa criadora, ele apresenta certa similaridade com o burocrata flexível, ou com o patriarca renovador (aqui, a autonomia do patriarca é de menor amplitude, em relação ao anterior) ou ainda com o líder com traços carismáticos mitigados. A sua prioridade é ajustar a empresa às novas demandas e necessidades que surjam.

De todo o modo, o ímpeto do agente transformador ou, em menor intensidade, do agente adaptador, para modificar a configuração organizacional-administrativa da empresa, não se mantém com o mesmo vigor indefinidamente, porquanto a organização empresarial necessita de certo nível de coesão e regularidade para operar e subsistir. Daí, quando os efeitos de sua ação propiciam a passagem da organização para um estado satisfatório, mesmo que não seja necessariamente o pretendido, ele se empenhará em garantir a sua continuidade, isto é, ele passará a agir à semelhança de um agente conservador até que vislumbre uma nova situação que possibilite outros esforços no sentido de implementar novas transformações.

Para propiciar um quadro de referências em relação ao qual uma empresa encontrada na realidade prática possa ser mais bem analisada, proponho três tipos estruturais, que podem ser decompostos em quatro subtipos.

- O tipo estrutural ordenativo-conservador. Uma empresa na qual prevalece a estabilidade, a ordem, a reverência ao preexistente, a obediência às regras e o exercício de práticas gerenciais orientadas pelos costumes, está associada ao tipo de organização ordenativo-conservadora, que decorre da combinação de 
elementos vinculados à burocracia rígida e ao patriarcado tradicionalista. $\mathrm{O}$ agente a ela correspondente é o conservador. Nessa situação, ocorre certa predominância do sistema-organização em relação à ação dos indivíduos. Esse tipo de empresa pode ser classificado em dois subtipos: o patriarcal conservador e o burocrático rígido.

. O tipo estrutural liberativo-transformador. No caso de uma empresa em que se enfatiza a mudança, a flexibilidade, a originalidade e a inovação, o tipo estrutural correspondente é o liberativo-transformador, fruto da combinação de componentes da liderança com traços carismáticos e do patriarcado reformador. O seu agente típico é o transformador. Nessas condições, a ação do agente tem certa primazia sobre o sistema-organização. Essa configuração organizacional-administrativa pode desdobrar-se nos seguintes subtipos: a empresa patriarcal reformista e a empresa centrada em líder de traços carismáticos.

. O tipo estrutural equiparativo-adaptador. Uma organização empresarial em que predomina um equilíbrio dinâmico mudança-conservação, flexibilidaderigidez, autonomia-controle e inovação-rotina, corresponde ao tipo estrutural equiparativo-adaptador, resultante da combinação de componentes da burocracia flexível, da liderança carismática mitigada e do patriarcado renovador. Essa é a estrutura-base originária do modelo. $\mathrm{O}$ agente associado a esse tipo é o adaptador. O modelo de organização empresarial que corresponde a esse tipo opera sob uma perspectiva que não privilegia nem o agente, nem o sistemaorganização.

Dessa maneira, para fins de análise organizacional, as formas de atuação dos agentes (conservador, transformador e adaptador) e a dinâmica interna do modelo podem ser sistematizadas em variados tipos estruturais (ordenativo, liberativo e equiparativo). O Quadro I, abaixo, resume a composição desses principais tipos estruturais de organização empresarial.

\section{Quadro I: Formação dos Tipos Organizacionais Derivados do Modelo}

\begin{tabular}{|l|l|l|}
\hline $\begin{array}{l}\text { Estrutura do tipo } \\
\text { equiparativo-adaptador } \\
\text { (configuração-básica) que } \\
\text { corresponde ao agente } \\
\text { adaptador }\end{array}$ & $\begin{array}{l}\text { Estrutura do subtipo } \\
\text { ordenativo-conservador } \\
\text { que corresponde ao agente } \\
\text { conservador }\end{array}$ & $\begin{array}{l}\text { Estrutura do subtipo } \\
\text { liberativo-transformador } \\
\text { que corresponde ao agente } \\
\text { transformador }\end{array}$ \\
\hline Burocracia flexível & Burocracia rígida & Burocracia incipiente \\
\hline Patriarcado renovador & Patriarcado conservador & Patriarcado reformista \\
\hline $\begin{array}{l}\text { Liderança com traços } \\
\text { carismáticos mitigados }\end{array}$ & $\begin{array}{l}\text { Liderança descarismatizada } \\
\text { (carisma objetivado) }\end{array}$ & $\begin{array}{l}\text { Liderança com acentuados } \\
\text { traços carismáticos }\end{array}$ \\
\hline
\end{tabular}


Nesses tipos de estruturas que emergem do modelo multidimensional, verificase um processo de organização-interações-reordenamento que decorre das transações da empresa com o seu ambiente externo, das inter-relações entre agentes, e entre estes e a estrutura organizacional. Em todo o caso, qualquer um daqueles tipos, ao suceder o outro, não o elimina totalmente, mas o absorve parcialmente em si, permutando-se alguns elementos de um para o outro, em processo contínuo de transformação. Vale dizer, a nova configuração estrutural não substitui totalmente a antiga, senão pela apropriação de algumas de suas características originais. Não ocorre, portanto, uma evolução linear, nem uma hierarquia previamente estabelecida de ascensão de um tipo inferior para outro superior, isto é, não há, passagem obrigatória ou seqüencial. Por exemplo, de uma estrutura ordenativo-conservadora para uma estrutura liberativotransformadora e, por fim, para uma estrutura equiparativo-adaptadora. Nesse sentido, cabe ter em conta que a afirmação da qualidade de uma organização empresarial está relacionada com a sua capacidade de propiciar funcionamento adequado e desempenho competitivo da empresa, em dado contexto.

\section{A Estrutura-típica do Modelo: a Organização Equiparativo-Adaptadora}

Uma organização empresarial correspondente ao tipo equiparativo-adaptador, estrutura-base do modelo de organização multidimensional, é constituída pelos seguintes elementos fundamentais: (1) a burocracia flexível, cujos elementos constituintes se distanciam consideravelmente dos componentes da burocracia típica, ou seja, a hierarquia de autoridade, o nível de regulamentação, a impessoalidade das relações, a padronização dos procedimentos, entre outros, ocorrem em baixa intensidade; (2) a liderança com traços carismáticos mitigados, isto é, desprovida da impetuosidade e do radicalismo transformador, próprios do carisma genuíno; e (3) o patriarcado renovador, em que costumes e práticas consuetudinárias são em grande parte superadas pelo livre arbítrio do patriarca, não obstante persistirem alguns elementos da tradição empresarial.

Em uma estrutura equiparativo-adaptadora tem-se, portanto, a conjugação de regras de conduta, liberdade criativa e alguns costumes invioláveis. A coexistência de rotinas, inovações e procedimentos consuetudinários reflete uma estreita articulação indivíduo-organização, mas não impede o seu agente representativo (adaptador) de gozar de certa autonomia para agir no sentido de adequar a empresa a novas necessidades e demandas, por meio de gradual implementação de mudanças. 
Na prática, a opção estrutural mais adequada para uma organização empresarial depende de um conjunto de fatores condicionantes, limitativos ou facilitadores, presentes em determinada situação. Por outro lado, não há um arranjo estrutural único e apropriado a todos os segmentos que compõem os diversos subsistemas sociotécnicos que constituem o sistema-empresa, seja por decorrência da especialização do trabalho, da descentralização regional, ou da diversidade educacional, entre outras razões de diferenciação interna. Assim, em uma mesma empresa ocorrem necessidades peculiares aos diversos setores especializados ou áreas funcionais, que exigem adequações estruturais. Uma dada empresa terá, por conseguinte, loci em que a inovação e os relacionamentos interpessoais são mais requisitados, e outros que necessitam de mais rotinas e impessoalidade.

O processo de mudança segundo o modelo multidimensional implica dizer que, quando um tipo estrutural é substituído por outro, este incorpora alguns elementos do anterior, quer dizer, a organização empresarial, ao mudar, não perde por completo e definitivamente todas as suas características originais. Essas transformações se manifestam basicamente de três formas: a primeira refere-se às situações em que ocorrem alterações na composição do tipo equiparativo-adaptador, sem perda da essência de sua identidade original; a segunda diz respeito às situações em que a sua estrutura é substancialmente modificada, propiciando condições para a sua migração, no sentido de outro tipo organizacional-administrativo; e a terceira corresponde a situações excepcionais que escapam a uma análise sistemática, nos termos do modelo multidimensional.

I) Podem ocorrer variações do tipo-base equiparativo-adaptador, sem que ele venha a perder todas as suas propriedades, embora a capacidade adaptativa da sua estrutura seja alterada. Observando-se o Quadro II, em relação à situação original, o grau de adaptabilidade a novas demandas tende a reduzir nas situações variantes A e C, e a aumentar no caso B, pois o potencial de ação do agente adaptador é, respectivamente, enfraquecido e fortalecido. 


\section{Quadro II: Variações Internas do Tipo-base Equiparativo-adaptador}

\begin{tabular}{|l|l|l|l|}
\hline $\begin{array}{l}\text { OMR do tipo } \\
\text { equiparativo- } \\
\text { adaptador } \\
\text { (situação original) }\end{array}$ & $\begin{array}{l}\text { Variante A do tipo } \\
\text { equiparativo-adaptador }\end{array}$ & $\begin{array}{l}\text { Variante B do tipo } \\
\text { equiparativo-adaptador }\end{array}$ & $\begin{array}{l}\text { Variante C do tipo } \\
\text { equiparativo- } \\
\text { adaptador }\end{array}$ \\
\hline Burocracia flexível & $\begin{array}{l}\text { Burocracia menos } \\
\text { flexível }\end{array}$ & $\begin{array}{l}\text { Burocracia mais } \\
\text { flexível }\end{array}$ & $\begin{array}{l}\text { Burocracia flexível } \\
\text { Patriarcado renovador }\end{array}$ \\
\hline Patriarcado renovador & $\begin{array}{l}\text { Fraca presença, ou } \\
\text { eventual ausência, da } \\
\text { dimensão patriarcal } \\
\text { renovadora }\end{array}$ & $\begin{array}{l}\text { Fraca presença, ou } \\
\text { eventual ausência, da } \\
\text { dimensão patriarcal } \\
\text { renovadora }\end{array}$ \\
\hline $\begin{array}{l}\text { Liderança com traços } \\
\text { carismáticos mitigados }\end{array}$ & $\begin{array}{l}\text { Fraca presença, ou } \\
\text { eventual ausência, da } \\
\text { dimensão liderança } \\
\text { carismática moderada }\end{array}$ & $\begin{array}{l}\text { Liderança com traços } \\
\text { carismáticos mitigados }\end{array}$ & $\begin{array}{l}\text { Fraca presença, ou } \\
\text { eventual ausência, da } \\
\text { dimensão liderança } \\
\text { carismática moderada }\end{array}$ \\
\hline
\end{tabular}

II) Casos em que variações nos componentes da configuração-base equiparativoadaptadora propiciam condições para a sua transição para outros tipos estruturais:

II.1) Ocorre a possibilidade de migração do tipo equiparativo-adaptador para o ordenativo-conservador, nas condições resumidas no Quadro III, seguinte.

\section{Quadro III: Transição do Tipo-base para a Estrutura Ordenativo-conservadora}

\begin{tabular}{|c|c|c|c|}
\hline $\begin{array}{l}\text { OMR equiparativo- } \\
\text { adaptador } \\
\text { (tipo-base) }\end{array}$ & Burocracia flexível & $\begin{array}{l}\text { Patriarcado } \\
\text { renovador }\end{array}$ & $\begin{array}{l}\text { Liderança carismática } \\
\text { moderada }\end{array}$ \\
\hline $\begin{array}{l}\text { Transição por } \\
\text { descarismatização, } \\
\text { burocratização } \\
\text { tradicionalização } \\
\text { (tipo ordenativo- } \\
\text { conservador) }\end{array}$ & $\begin{array}{l}\text { Maximização } \\
\text { presença e da } \\
\text { intensidade dos } \\
\text { componentes da } \\
\text { dimensão burocrática } \\
\text { (burocracia rígida) }\end{array}$ & $\begin{array}{l}\text { Maximização da área } \\
\text { objetiva estritamente } \\
\text { ligada à tradição e } \\
\text { minimização da esfera } \\
\text { de livre arbítrio do } \\
\text { patriarca } \\
\text { (patriarcado } \\
\text { conservador) } \\
\end{array}$ & $\begin{array}{ll}\text { Minimização } & \text { da } \\
\text { dimensão liderança } & \\
\text { carismática } & \end{array}$ \\
\hline $\begin{array}{l}\text { Transição por } \\
\text { burocratização, } \\
\text { destradicionalização e } \\
\text { descarismatização } \\
\text { (subtipo burocracia } \\
\text { rígida) }\end{array}$ & $\begin{array}{l}\text { Maximização } \\
\text { presença e da } \\
\text { intensidade } \\
\text { componentes dos } \\
\text { dimensão burocrática } \\
\text { (burocracia rígida) }\end{array}$ & $\begin{array}{l}\text { Minimização } \\
\text { dimensão patriarcal }\end{array}$ & $\begin{array}{ll}\text { Minimização } & \text { da } \\
\text { dimensão liderança } & \\
\text { carismática } & \end{array}$ \\
\hline $\begin{array}{l}\text { Transição por } \\
\text { tradicionalização, } \\
\text { desburocratização e } \\
\text { descarismatização } \\
\text { (subtipo patriarcado } \\
\text { conservador) }\end{array}$ & $\begin{array}{l}\text { Minimização } \\
\text { presença e da } \\
\text { intensidade } \\
\text { componentes dos } \\
\text { dimensão burocrática } \\
\text { (burocracia incipiente) }\end{array}$ & $\begin{array}{l}\text { Maximização da área } \\
\text { objetiva estritamente } \\
\text { ligada à tradição e } \\
\text { minimização da esfera } \\
\text { de livre arbítrio do } \\
\text { patriarca } \\
\text { (patriarcado } \\
\text { conservador) } \\
\end{array}$ & $\begin{array}{ll}\text { Minimização } & \text { da } \\
\text { dimensão liderança } & \\
\text { carismática } & \end{array}$ \\
\hline
\end{tabular}


II.2) Existe também a possibilidade de transição do tipo equiparativo-adaptador para o liberativo-transformador, nas seguintes situações:

\section{Quadro IV: Transição do Tipo-base para a Estrutura Liberativo-transformadora}

\begin{tabular}{|c|c|c|c|}
\hline $\begin{array}{l}\text { OMR equiparativo- } \\
\text { adaptador } \\
\text { (tipo-base) }\end{array}$ & Burocracia flexível & $\begin{array}{l}\text { Patriarcado } \\
\text { renovador }\end{array}$ & $\begin{array}{l}\text { Liderança carismática } \\
\text { moderada }\end{array}$ \\
\hline $\begin{array}{l}\text { Transição por } \\
\text { destradicionalização, } \\
\text { carismatização } \\
\text { desburocratização } \\
\text { (tipo liberativo- } \\
\text { transformador) }\end{array}$ & $\begin{array}{l}\text { Minimização } \\
\text { presença e da } \\
\text { intensidade dos } \\
\text { componentes da } \\
\text { dimensão burocrática } \\
\text { (burocracia incipiente) }\end{array}$ & $\begin{array}{l}\text { Maximização da esfera } \\
\text { de livre arbítrio do } \\
\text { patriarca (incremento } \\
\text { da subjetividade) e } \\
\text { minimização da área } \\
\text { relacionada com a } \\
\text { tradição } \\
\text { (patriarcado reformista) }\end{array}$ & $\begin{array}{l}\text { Maximização da } \\
\text { dimensão liderança } \\
\text { carismática } \\
\text { (liderança empresarial } \\
\text { com traços } \\
\text { carismáticos) }\end{array}$ \\
\hline $\begin{array}{l}\text { Transição por } \\
\text { carismatização, } \\
\text { destradicionalização e } \\
\text { desburocratização } \\
\text { (subtipo - estrutura } \\
\text { centrada no líder) }\end{array}$ & $\begin{array}{l}\text { Minimização da } \\
\text { presença e da } \\
\text { intensidade dos } \\
\text { componentes da } \\
\text { dimensão burocrática } \\
\text { (burocracia incipiente) }\end{array}$ & $\begin{array}{l}\text { Minimização } \\
\text { dimensão patriarcal }\end{array}$ & $\begin{array}{l}\text { Maximização da } \\
\text { dimensão liderança } \\
\text { carismática } \\
\text { (liderança empresarial } \\
\text { com traços } \\
\text { carismáticos) }\end{array}$ \\
\hline $\begin{array}{l}\text { Transição por } \\
\text { destradicionalização, } \\
\text { desburocratização e } \\
\text { descarismatização } \\
\text { (subtipo patriarcado } \\
\text { reformista) }\end{array}$ & $\begin{array}{l}\text { Minimização } \\
\text { presença e da } \\
\text { intensidade dos } \\
\text { componentes da } \\
\text { dimensão burocrática } \\
\text { (burocracia incipiente) }\end{array}$ & $\begin{array}{l}\text { Maximização da esfera } \\
\text { de livre arbítrio do } \\
\text { patriarca (incremento } \\
\text { da subjetividade) e } \\
\text { minimização da área } \\
\text { relacionada com a } \\
\text { tradição (patriarcado } \\
\text { reformista) }\end{array}$ & $\begin{array}{l}\text { Minimização da } \\
\text { dimensão carismática }\end{array}$ \\
\hline
\end{tabular}

III) Por fim, cabe identificar situações extraordinárias, que escapam a uma análise sistemática com base no modelo proposto.

III.1) O antagonismo burocracia-carisma. Se ocorresse a total ausência da dimensão patriarcal e a maximização da presença e da intensidade dos componentes das dimensões burocrática e carismática, até os limites dos seus tipos puros correspondentes, ter-se-ia uma situação de antagonismos que extrapolaria o escopo de análise do modelo, porquanto, se existisse na prática, representaria profunda instabilidade estrutural que levaria à degenerescência da empresa.

III.2) O retorno aos tipos ideais. Na hipótese absurda de os três conjuntos de elementos constituintes do tipo equiparativo-adaptador se fortalecerem ao ponto de se aproximarem dos seus respectivos conceitos-limites, ter-se-ia uma situação não observável na realidade empresarial, cuja análise, portanto, foge aos propósitos do modelo. 
III.3) A ausência de componentes burocráticos. Na situação meramente especulativa em que a organização empresarial não possuísse nenhum dos elementos constituintes da burocracia, ou seja, diante de um quadro de total inadequação meios-fins, ou de absoluta ineficiência administrativa, em que a empresa estivesse desprovida de ações racionais em relação a objetivos, terse-ia uma insuperável incompatibilidade com a noção de empreendimento econômico, implicando, por conseguinte, um fenômeno fora do alcance de aplicação do modelo.

III.4) O confronto radical conservação-mudança. Se uma empresa hipotética apresentasse as dimensões patriarcal e carismática próximas dos seus respectivos tipos ideais, ter-se-ia por resultante um estado interativo das forças mantenedoras da tradição e das forças promotoras da mudança que se anulariam reciprocamente, impedindo o funcionamento regular da organização.

III.5) Um “conjunto vazio". Na situação em que as três dimensões se enfraquecem ao ponto de se descaracterizarem em relação aos seus tipos ideais correspondentes, ou seja, quando os elementos constituintes da estrutura equiparativo-adaptadora se tornam praticamente ausentes, a configuração-base do modelo tenderia para um conjunto vazio.

\section{Breve Caracterização da Empresa Ordenativo-conservadora}

A organização empresarial que corresponde ao tipo ordenativo-conservador possui uma estrutura formada pela combinação de componentes que definem uma burocracia rígida e de elementos que constituem um patriarcado conservador, em que o patriarca pouco exercita o seu livre arbítrio. A propósito dessa configuração, é oportuno sublinhar que a possibilidade analítica de o patriarcado ser decomposto em duas vertentes - a sacralidade do passado e a reverência para com o precedente estabelecido - torna compatível sua coexistência com a burocracia, a qual efetiva suas regras e rotinas também com base no "precedente estabelecido" ou na experiência pretérita recorrente. Uma organização com estrutura ordenativo-conservadora é marcada pela resistência à mudança, restrição à autonomia criativa, pouca liberdade para inovar e pela profusão de regulamentos e práticas consuetudinárias. Com tais características ela tem dificuldades em operar satisfatoriamente em ambiente complexo, dinâmico e competitivo. No entanto, essa estrutura pode representar alternativa para uma empresa em meio a um estado de profunda desordem, de absoluta falta de comando ou de total imobilismo pela inexistência de diretrizes. 
O tipo ordenativo-conservador está sujeito a variações internas, podendo apresentar duas configurações estruturais derivadas, a saber: (1) o subtipo empresa patriarcal conservadora, quando se tem minimizada a presença e a intensidade de componentes burocráticos; e (2) o subtipo empresa burocrática rígida, quando não se tem a presença de componentes patriarcais.

Com o crescimento de uma empresa ordenativo-conservadora e a intensificação de demandas endógenas e exógenas, a sua estrutura tende a se modificar e a sua gestão é pressionada para desconcentrar o processo decisório, descentralizar as operações, alterar procedimentos padronizados, substituir práticas tradicionais e inovar na oferta de produtos ou serviços. Nessas circunstâncias de expansão dos negócios e de complexificação do seu gerenciamento, pode tornar-se inevitável à empresa romper com a ordem estabelecida, a despeito das resistências internas. Para tanto, ela poderá encaminhar-se no sentido de adotar configurações organizacional-administrativas menos burocráticas e/ou menos tradicionalistas, possibilitando uma maior autonomia dos agentes para influírem sobre o destino da empresa e fazendo-a migrar para o tipo equiparativo-adaptador ou liberativotransformador.

A empresa correspondente ao subtipo ordenativo-conservador patriarcal possui uma configuração organizacional-administrativa centrada na pessoa do patriarca e estreitamente ligada aos hábitos e costumes forjados em sua trajetória históricocultural. Nela são ressaltados o respeito aos tempos idos, a obediência às práticas preexistentes, a ênfase na experiência pretérita e a lealdade ao dirigente-patriarca. Cabe reiterar que, como em qualquer empreendimento econômico, a empresa patriarcal conservadora acolhe uma burocracia incipiente, não obstante o culto às suas tradições.

Para Weber (1974, p. 250 e 251), as grandes empresas capitalistas encontravam na burocracia as suas características essenciais: "quanto mais complicada e especializada se torna a cultura moderna, tanto mais seu aparato de apoio externo exige o perito despersonalizado e rigorosamente 'objetivo', em lugar do 'mestre' das velhas estruturas sociais, que era movido pela simpatia e preferência pessoais, pela graça e gratidão". Ele também considerava que a racionalização burocrática tem sido ao longo da história uma força modernizante contra a inércia da tradição, transformando as organizações e os homens de fora para dentro (ao contrário do carisma que os modifica de dentro para fora). O reconhecimento da importância histórica do processo de burocratização não impedia Weber de considerá-lo como "mal inevitável” que, quando se estabelece em sua plenitude, está entre as estruturas mais difíceis de serem destruídas ou mesmo modificadas. A avaliação de Weber do funcionamento da burocracia tinha mais em vista o contexto estatal do que o ambiente econômico privado. É também provável que 
ele se tenha inspirado em sua experiência como coordenador de treze hospitais militares alemães, durante a Primeira Guerra Mundial (Kaesler, 1996). Uma organização intensamente burocratizada apresenta rigidez estrutural que carece de fortes intervenções flexibilizadoras para melhor operar em um regime de elevada competitividade, muito embora, à semelhança da burocracia pública, resista vigorosamente às alterações necessárias.

Afora os inúmeros exemplos de organizações existentes no setor público, não são muito freqüentes os casos de empresas privadas enquadráveis no subtipo burocracia rígida, uma vez que a complexa dinamicidade do ambiente atualmente requer estruturas capazes de se ajustarem às exigências do cliente e à competição no mercado. Algumas empresas do segmento de segurança privada talvez sejam exemplos desse subtipo, devido à natureza de suas atividades e pela sua origem geralmente calcada em instituições policiais.

Malgrado a sua genialidade, Weber não conseguiu vislumbrar que, na prática, a organização empresarial burocrática tem sempre presente o risco de as regras serem encaradas como fim em si mesmas, perdendo-se o foco nos resultados e invertendo-se a relação meios-fins. Nesse sentido, a qualidade do desempenho empresarial, requerida atualmente pelo mercado, é contrariada por grande parte dos componentes burocráticos, como: excessiva impessoalidade, regulamentações detalhistas, estrita obediência às ordens, divisão do trabalho inflexível, relações verticais fortemente hierarquizadas etc. De outra parte, a presumida vinculação entre burocracia e racionalidade formal é imperfeita, na medida em que os agentes nem sempre articulam de maneira efetivamente racional os meios e recursos disponíveis para atingirem os objetivos organizacionais, pois eles têm limitada capacidade de armazenar, interpretar e processar informações complexas, o que os leva a agir mais com base no conhecimento suficiente e raramente no conhecimento completo (Simon, 1971; Udy, 1959).

\section{Breve Caracterização da Empresa Liberativo-transformadora}

O tipo liberativo-transformador é uma configuração organizacionaladministrativa que decorre da combinação de componentes do patriarcado reformista e da liderança com traços carismáticos, sendo, por conseguinte, uma estrutura à qual corresponde o agente transformador (combinação de elementos constituintes do patriarca reformador e do líder empresarial com traços carismáticos). Dos tipos estruturais derivados do modelo, esse é o que oferece melhores condições para se implementarem transformações, pois nele ocorre a convergência de dois vetores de mudança: (1) o de maior intensidade é 
representado pela ação do líder empresarial com traços carismáticos; e (2) o outro corresponde à conduta reformista do patriarca, que se vale ao máximo da sua esfera de livre arbítrio para modificar práticas tradicionais da empresa. Marcada pela presença de componentes carismáticos e patriarcais reformistas, a organização empresarial que corresponde ao tipo estrutural liberativotransformador acolhe componentes burocráticos de maneira incipiente, ou seja, em intensidade mínima em relação ao seu tipo ideal. Entretanto, para possibilitar a sua sobrevivência e crescimento, ela busca certo nível de eficiência, adequando os meios e recursos aos seus objetivos, isto é, ao lado de ingredientes tradicionais e afetivos existe certo grau de racionalidade instrumental.

A estrutura liberativo-transformadora ocorre com maior freqüência nos períodos iniciais da empresa. A saga de vários empreendimentos econômicos que se transformaram em organizações empresariais sólidas e duradouras é povoada por líderes visionários e com traços carismáticos. Mas, em qualquer época, podem surgir pré-condições favoráveis à sua manifestação, notadamente quando a empresa se encontra inerte diante de graves ameaças, em momentos de crise aguda ou em situações de profundo inconformismo com a situação vigente. Nessas circunstâncias extremas, tem-se enfatizado a necessidade de transformações imediatas e tende-se a magnificar a missão salvadora e a conduta exemplar de um agente transformador, seja ele patriarca reformista ou líder empresarial com traços carismáticos, apesar de isso não garantir as mudanças necessárias, porquanto, muitas vezes, "desejos e oportunidades variam em direção oposta com a adversidade das circunstâncias” (Elster, 1994, p. 34).

Na empresa liberativo-transformadora valoriza-se mais o inédito do que o predeterminado; ressaltam-se as oportunidades, em detrimento das restrições; incentivam-se novas formas de agir, em lugar de defender as antigas; acolhe-se o confronto de idéias e argumentos, em lugar do conformismo ou da imposição de soluções pela via hierárquica ou amparadas na tradição. Cabe sublinhar que a organização empresarial que apresenta essa configuração é instável e efêmera, por conta de sua natureza essencialmente personalística. Em geral, ultrapassado o período crítico que implicou as condições propícias para as mudanças e consolidado o reordenamento da empresa, tendem a enfraquecer-se o extraordinário relacionamento interpessoal e a força dos ideais entusiasmantes que sustentaram as interações precedentes às transformações. A configuração organizacional liberativo-transformadora pode ser desdobrada em dois subtipos, dependendo da principal base sobre a qual se desenvolve a ação do agente transformador: (1) se as ações estão originalmente legitimadas na tradição empresarial, embora o patriarca exerça plenamente a sua área autônoma de avaliação subjetiva, tem-se o subtipo patriarcal reformista; (2) se as ações que se verificam na empresa se fundamentam em extraordinários atributos pessoais 
do agente, tem-se o subtipo liberativo-transformador centrado em líder com traços carismáticos.

A configuração patriarcal reformista é representada por uma organização empresarial dotada de estrutura liberativo-transformadora que ressalta a área de livre arbítrio do patriarca que, liberto em grande parte das amarras impostas pela tradição (salvaguardados alguns costumes invioláveis), é capaz de promover algumas reformas indispensáveis para atender às exigências internas e ambientais que surgem.

Os períodos de grande incerteza e de crise profunda em uma organização empresarial, que acarretam sensações de perda, ausência de sentido e temor pelo caos, preparam o terreno para o carisma e constituem forte incentivo para a busca por algo "superior", em geral representado por um líder com traços carismáticos. Dessa personagem que desperta admiração, confiança e reverência, espera-se o desempenho de múltiplos papéis: mentor, protetor, unificador do grupo, libertador das incertezas e portador de futuro melhor. Tenha-se em conta que, em dado contexto empresarial, o surgimento de um líder com traços carismáticos decorre de processo que envolve a sua personalidade e habilidades, as crenças ou objetivos compartilhados, o vínculo afetivo entre os integrantes da empresa e a interação destes com o líder, cuja capacidade de realização é potenciada pelo seu estoque de conhecimentos e pela sua trajetória de sucesso.

Importante ressaltar que a empresa centrada em um líder com traços carismáticos corresponde ao potencial máximo da ação voluntarista para a mudança organizacional, notadamente quando ele é o proprietário e principal dirigente da empresa, circunstância que pode viabilizar o seu ímpeto empreendedor sem praticamente nenhuma limitação, obviamente salvo a ocorrência de fatores restritivos imprevisíveis e não controláveis. O líder empresarial de traços carismáticos não tem necessariamente assegurado o seu êxito, pois exatamente as suas características pessoais, que despertam paixões e mobilizam vontades, podem pôr em risco o negócio. De fato, não é de sua natureza orientar os integrantes da sua empresa a tratarem com questões recorrentes, que estão associadas à regularidade do seu funcionamento e à estabilidade de suas operações. Na estrutura extremamente personalista que marca a empresa centrada em um líder, praticamente não há formalidades, nem regulamentações, sendo a organização dotada de grande flexibilidade. Nela, acolhe-se uma íntima e forte interação dos seus integrantes, cultiva-se devoção ao líder, consagra-se a sua visão de futuro para a empresa e reverencia-se a sua conduta exemplar. Não obstante a confiança e fidelidade dos empregados-seguidores para com o líder empresarial, essa é a mais instável das estruturas organizacionais derivadas do modelo. Pela absoluta dependência da empresa de um único indivíduo, quando 
este fracassa na concretização de suas idéias e planos, a organização quase sempre envolve-se em crise que pode levá-la ao desaparecimento ou a assumir outra configuração estrutural.

\section{Considerações Finais}

O modelo multidimensional para análise de organizações empresariais assume o desiderato de articular a flexibilidade, a autonomia e a liberdade, que propiciam a inovação e a criatividade, com a estabilidade e as regras e a padronização, que favorecem a disciplina administrativa e o controle gerencial. Esse modelo, porém, recusa o simplismo de representar esses fenômenos como meras justaposições de contrários e rejeita o maniqueísmo dualista do 'ou-um-ou-outro'. Vale dizer, ele incorpora, além das transações ambiente-empresa, a dinâmica coexistência daquele conjunto de fenômenos, a um só tempo opostos e complementares, e considera que a empresa contemporânea opera em meio a um processo permanente de organização-interações-reordenamento. Para o modelo proposto, os agentes organizacionais podem conceber novos desenhos de estrutura e novas configurações administrativas que propiciem a competitividade da empresa e uma ambiência sociotécnica mais condizente com as necessidades humanas, isto é, uma organização empresarial que se afaste da tradição que imobiliza, da liderança carismática que se basta por si mesma e da impessoalidade da burocracia.

A estrutura do tipo equiparativo-adaptadora, tipo-base do modelo multidimensional, procura aproximar-se da realidade prática: não subestima a importância da tradição, mas a renova; não repudia a liderança carismática, mas a acolhe mitigada; não tem a veleidade do desprezo pela burocracia, mas a flexibiliza.

Este trabalho procurou encaminhar algumas tentativas de respostas, por meio dos tipos e subtipos estruturais originados do modelo multidimensional. Mas todos eles ainda carecem de pesquisas de campo, para que sejam aperfeiçoados teoricamente e avaliadas, na prática, a sua utilidade analítica. Por não se tratar exatamente de teoria, o modelo multidimensional possui alcance limitado, indicando apenas possíveis relações e propriedades associadas à organização empresarial. Para que esse modelo possa contribuir para a geração de teorias, ele precisa ser submetido a testes empíricos rigorosos que venham a possibilitar a inclusão ou exclusão de predicados que o habilite a melhor descrever e interpretar a realidade empresarial. De outra parte, o modelo apresenta em sua genealogia os tipos 
ideais de dominação, que é uma perspectiva centrada na autoridade. Ele realça, nos tipos estruturais propostos, mais a atuação e a perspectiva dos dirigentes e líderes empresariais do que as crenças e motivações para agir que suscitam da parte dos subordinados e seguidores. Assim, é por demais relevante também avaliar criticamente o modelo, sob a ótica dos dominados.

\section{Artigo recebido em 02.10.2002. Aprovado em 13.10.2003.}

\section{RefERÊNCIAS Bibliográficas}

\section{ALVES, S.}

Revigorando a cultura da empresa.

São Paulo: Makron Books, 1997.

\section{ARON, R.}

As etapas do pensamento sociológico.

São Paulo: M. Fontes, 1993.

BENDIX, R.

Weber: um retrato intelectual. Brasília: UNB, 1986.

\section{CAVALCANTI, $\mathrm{R}$.}

As origens do coronelismo. Recife: UFPE, 1984.

\section{CHANLAT, J.F.}

Ciências sociais e management: reconciliando o econômico e social. São Paulo: Atlas, 2000.

\section{DELLAGNELO, E.L.;}

MACHADO-DA-SILVA, C. L.

Literatura sobre novas formas organizacionais: onde se encontram as evidências empíricas de ruptura com o modelo burocrático de organizações? In: ENCONTRO ANUAL DA ANPAD, 24., 2000, Florianópolis. Anais... Florianópolis: ANPAD, 2000.
ELSTER, J.

Peças e engrenagens das ciências sociais. Rio de Janeiro: Relume Dumará, 1994.

ENRIQUEZ,E.

Da horda ao Estado: psicanálise do vínculo social. Rio de Janeiro: Zahar, 1990.

ETZIONI, A.

Organizações modernas. São Paulo: Pioneira, 1974.

FAORO, R.

Os donos do poder. Rio de Janeiro:

Globo, 1976.

FREITAS, M. E.

Cultura organizacional: identidade, sedução e carisma? Rio de Janeiro: FGV,1999.

GODBOUT, J.

O espírito da dádiva. Lisboa: Inst. Piaget, 1997.

GIDDENS, A.

New rules of sociological method. Cambridge: Polity Press, 1993. 
GUSMÃO, L.

A concepção de causa na filosofia das ciências sociais de Max Weber. In: SOUZA, J. (Org.). A atualidade de

Max Weber. Brasília: UNB, 2000.

KAESLER, D.

Max Weber. Paris: Fayard, 1996.

MARCH, J. G.;

SIMON, H. A.

Teoria das organizações. Rio de Janeiro: FGV, 1967.

MATOS, A. G.

A intervenção sociológica. In: Estudos de Sociologia, Recife, n. 1, v. 6, jan./jun. p. 55-72, 2000.

MINTZBERG, $\mathrm{H}$.

Criando organizações eficazes: estruturas em cinco configurações. São Paulo: Atlas, 1995.

MOTTA, P. R.

Gestão contemporânea: a ciência e a arte de ser dirigente. Rio de Janeiro: Record, 1997.

OUCHI, W.

Teoria Z. São Paulo: Fundo Educativo Brasileiro, 1982.

PUGH, D. S.;

HICKSON, D. J.;

HINNINGS, C. R.

An empirical taxonomy of work organization. Administrative Science Quarterly, New York, v.14, n.1, 1968.
REIS, F. W.

Weber e a ciência social atual: notas sobre três temas. In: SOUZA, J. (Org.). A atualidade de Max Weber. Brasília: Ed. UNB, 2000.

SIMON, H. A.

Comportamento administrativo. Rio de Janeiro: FGV, 1971.

UDY, S.

Burocracy and rationality in Weber's organization theory: an empirical study. American Sociological Review, Albany, N.Y., v. 4, n. 6, 1959.

URICOECHEA, F.

O minotauro imperial: a burocratização do Estado patrimonial brasileiro no século XIX. São Paulo: Difel, 1978.

WEBER, M.

Economia e sociedade. Revisão técnica de Gabriel Cohn. Brasília: UNB, 1999.

Ensaios de sociologia. Organização e introdução de H. H. Gerth e C. W. Mills. Rio de Janeiro: Zahar Editores, 1974.

WOLPERT, J.

Toward a sociology of authority. In: GOULDNER, A. W. (Ed.). Studies in leadership. New York: The Free Press, 1950. 